\title{
Nodular Hidradenoma - A Rare Case Report
}

\author{
Nivethitha Ayyasamy Chandran ${ }^{1}$, Ramachandran Ramakrishnan ${ }^{2}$, Murali Narasimhan ${ }^{3}$ \\ 1, 2,3 Department of Dermatology, Venereology and Leprosy, SRM Medical College \\ Hospital and Research Institute, Potheri, Chengalpattu, Tamil Nadu, India.
}

\section{INTRODUCTION}

Appendageal tumours present unique difficulties in diagnosis both clinically and histologically as there may be an admixture of follicular, eccrine, sebaceous and / or apocrine differentiation. Sweat gland neoplasms are extremely rare neoplasms. They can be classified into benign and malignant variety. The benign variety has been sub divided into subtypes such as nodular, apocrine and clear cell, based on their histopathological presentation. The malignant form of sweat gland carcinomas are those that possess an infiltrative and / or metastatic potential. They are generally classified into two groups. Hidradenomas are rare benign cutaneous tumours of sweat gland origin. Nodular hidradenomas are uncommon benign adnexal neoplasms of either eccrine or apocrine origin or latter being the most common. Nodular hidradenomas are rare and have been reported under various designations such as eccrine spiradenoma, eccrine acrospiroma, solid-cystic hidradenoma, clear cell acrospiroma, clear cell myoepithelioma and eccrine sweat gland adenoma.

\section{PRESENTATION OF CASE}

A 47-year-old male patient presented with a slow growing swelling over the abdomen since 3 years. He gives history of gradual increase in the size of the lesion. There was no history of pain or any discharge from the lesion. There was no preceding history of trauma involving the affected area. The past- and family-history were unremarkable. Cutaneous examination revealed a solitary, sessile, globular, circumscribed reddish nodule measuring $1 \mathrm{~cm}$ in diameter over the abdomen. The nodule had a smooth surface, and on palpation, was soft in consistency and nontender. The swelling was non-blanching on diascopy. Excision biopsy was done and subjected to histopathological examination.

\section{DIFFERENTIAL DIAGNOSIS}

Pyogenic granuloma

Nodular hidradenoma

Hemangioma

Dermatofibroma.
Corresponding Author: Dr. Murali Narasimhan, Professor,

Department of Dermatology,

SRM Medical College Hospital and

Research Institute (SRMIST), Potheri,

Chengalpattu - 603203,

Tamil Nadu, India.

E-mail: leecutis2gmail.com

DOI: $10.14260 /$ jemds/2021/53

How to Cite This Article:

Chandran NA, Ramakrishnan $R$ Narasimhan M. Nodular hidradenoma - a rare case report. J Evolution Med Dent Sci 2021;10(04):243-245, DOI: $10.14260 / \mathrm{jemds} / 2021 / 53$

Submission 16-10-2020,

Peer Review 30-11-2020,

Acceptance 05-12-2020,

Published 25-01-2021.

Copyright (c) 2021 Nivethitha Ayyasamy Chandran et al. This is an open access article distributed under Creative Commons Attribution License [Attribution 4.0 International (CC BY 4.0)] 


\section{PATHOLOGICAL DISCUSSION}

The lesion was excised and sent for histopathological examination. Histopathology showed hyperkeratosis, irregular acanthosis, focal epidermal atrophy and papillomatosis. The dermis showed tumour composed of two types of cells arranged in lobules, intersected by thin fibrous septae. Certain areas showed wide cystic spaces lined by cuboidal cells. The solid portions of the tumour are composed of polyhedral cells with round nuclei and amphophilic cytoplasm. The other cells are round in shape with clear cytoplasm, distinct cell borders and small dark nuclei. There is no evidence of significant nuclear pleomorphism, brisk mitotic activity or infiltrative pattern.

\section{DISCUSSION OF MANAGEMENT}

Excision biopsy was done for investigative and therapeutic purposes.
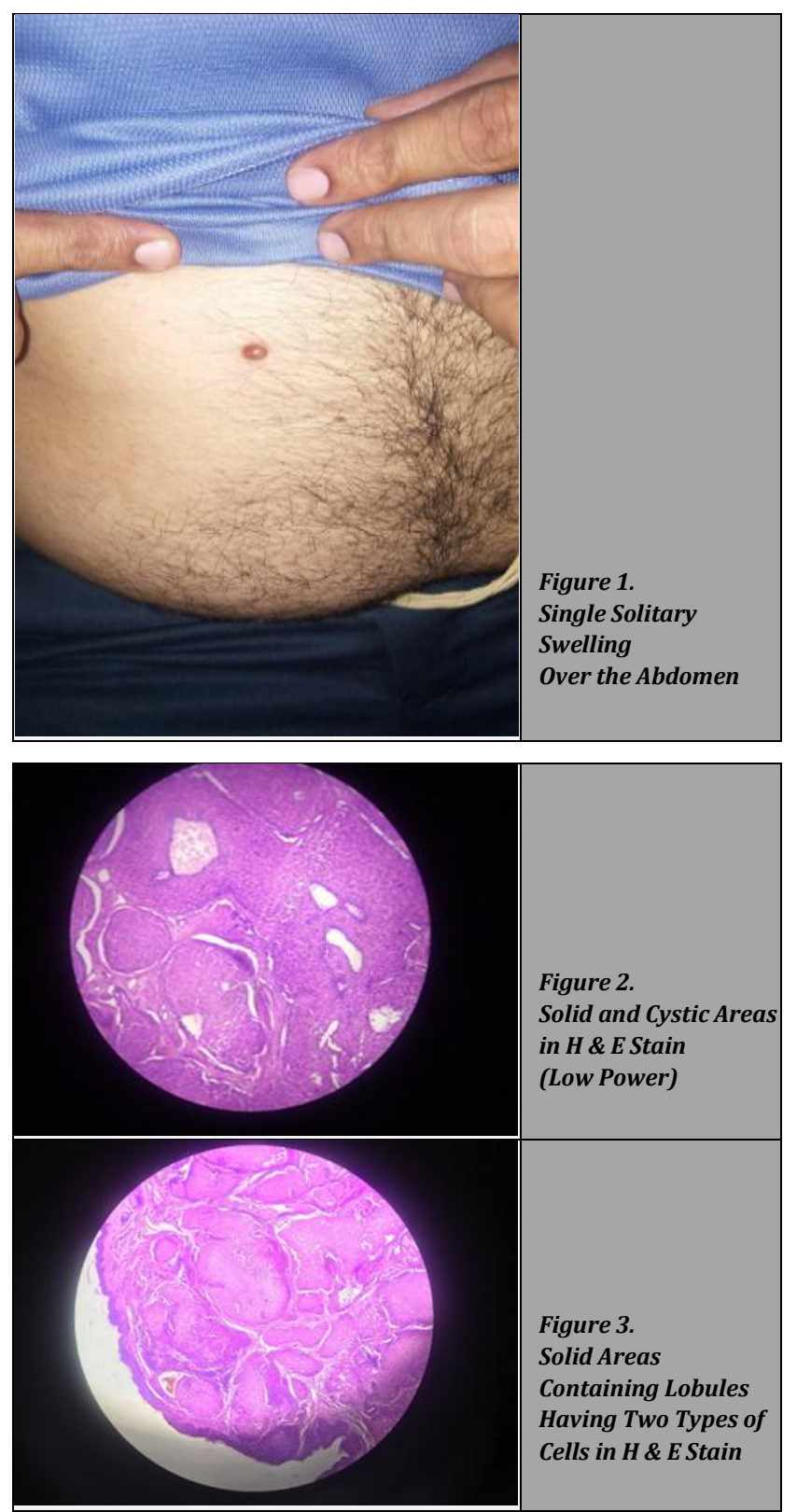

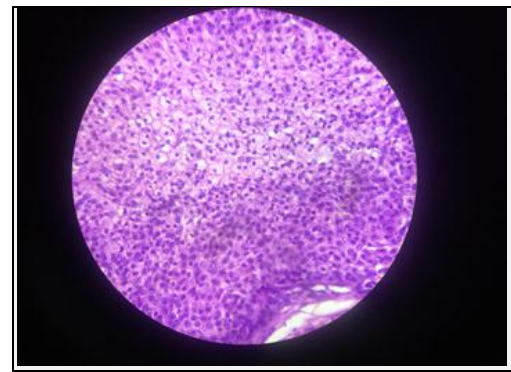

Figure 4.

Two Types of Cells:

Polyhedral Cells

and Basophilic Cytoplasm

Round Cells with Clear

Cytoplasm

\section{DISCUSSION}

Nodular Hidradenoma is a benign adnexal tumour that arises from the distal excretory duct of eccrine sweat glands. Its incidence is 5 per one million cases. Nodular hidradenomas are usually seen in the $4^{\text {th }}$ to $8^{\text {th }}$ decade of life. It is twice more common in females than in males. It usually presents as slowly enlarging, solitary, freely movable nodule, solid or cystic, measuring on an average $0.5-2 \mathrm{~cm}$ in diameter, but may reach $6.0 \mathrm{~cm}$ or more. The lesion occurs anywhere on the body e.g. axilla, face, arms, thighs, trunk, scalp and pubic region but the most common site is head.1,2 Ocasionally brown, blue or red discoloration and surface erosions or ulceration may be observed. Rapid growth may represent trauma, haemorrhage or a malignant change.2,3,4,5 Atypical sites of presentation include caruncle and oral cavity. Some tumours discharge serous material while others tend to ulcerate. Our patient was asymptomatic, with no history of pain or discharge. Clinical differential diagnoses can include dermatofibroma, solitary neurofibroma, pyogenic granuloma, melanoma, metastatic tumor, cherry angioma, hemangioma, leiomyoma and other cutaneous adnexal tumors. However, histology can reliably exclude all the other possibilities. Immunohistochemical staining may be done for further confirmation. ${ }^{6}$ Histopathological characteristic features of nodular hidradenoma are distinct. They are well circumscribed, encapsulated and sharply demarcated from the epidermis by Grenz zone. The tumor is composed of solid and cystic spaces. Solid areas reveal the presence of epithelial lobules comprising of two types of cells. Predominant cell type is the polyhedral cells with more basophilic cytoplasm and the other cell type is round, with a clear cytoplasm, due to the presence of glycogen. ${ }^{7}$ the Histopathological features in our patient showed relatively similar findings.

One limitation in our approach was that immunohistochemical studies were not done since the patient was satisfied with the diagnosis and was not willing for further immunohistochemical studies. Malignant nodular hidradenoma (MNHs), especially the metastasizing type is an extremely aggressive neoplasm with a very poor clinical outcome. MNHs are usually large, poorly demarcated, and asymmetric lesions as compared with the typically welldemarcated benign variant. The distinction is based on lack of circumscription, infiltrative manner of spread, nuclear pleomorphism, perineural and lymphovascular invasion and increased mitotic figures. Haematogenous spread to distant nodes, bones, and lungs and other organs can occur.6,8,9 Positive immunohistochemical staining for keratin, epithelial membrane antigen(EMA), carcinoembryonic antigen(CEA) S 100 protein and vimentin is characteristic and is typically negative for Oestrogen receptors (ER) progesterone receptors 
(PR) and smooth muscle actin. ${ }^{10}$ Dermoscopic features of pigmented nodular hidradenoma include a pattern composed of a bluish homogeneous area which occupies the whole lesion, with vascular and white structures. The same pattern with a pinkish colouration is the most frequent feature in nonpigmented $\mathrm{NH}$. Nodular hidradenoma is labelled as atypical when there is no evidence of invasive features but it has a high mitotic rate or nuclear atypia. The exact frequency of nodular hidradenoma and their risk of transformation into malignant tumours is not known. However, mitotic activity and cellular pleomorphism may not be accurate predictors of clinical behavior. Malignant nodular hidradenoma are usually known to arise de novo and malignant transformation of benign nodular hidradenoma has rarely been reported. Treatment of benign, atypical and malignant nodular hidradenoma is surgical excision with adequate margins to minimize the risk of recurrence followed by histologic confirmation. ${ }^{11}$

\section{FINAL DIAGNOSIS}

Nodular hidradenoma.

\section{CONCLUSIONS}

Nodular hidradenoma is an uncommon benign adnexal neoplasm of eccrine or apocrine origin. Clinical suspicion is essential and excision biopsy would be the preferred initial investigation and management of solitary nodular hidradenoma. Different adnexal tumours could have similar clinical features and hence, histopathological examination of the tumour is essential to identify the tumours and whether it is benign or malignant. Therefore, a takeaway point from this case report would be that identification of the type of benign adnexal tumours is important because different adnexal tumours can have varied risk of malignant transformation, Since MNHs usually occur in a de novo pattern, the risk of malignant degeneration of benign hidradenoma is very low.

Financial or other competing interests: None.

Disclosure forms provided by the authors are available with the full text of this article at jemds.com.

\section{REFERENCES}

[1] Elder D, Elenitsas R, Ragsdale BD. Tumors of the epidermal appendages. In: Elder D, Elenitsas R, Jaworsky C, et al. eds. Lever's Histopathology of the Skin. $8^{\text {th }}$ edn. Philadelphia: Lippincott Williams and Wilkins 1997: p. 747-803.

[2] Wilhelmi BJ, Appelt EA, Phillips LG. A rare case of atypical eccrine acrospiroma of the scalp and a literature review. Ann Plast Surg 1999; 42(5):568-9.

[3] Biddlestone LR, Mclaren KM, Tidman MJ. Malignant hidradenoma--a case report demonstrating insidious histological and clinical progression. Clin Exp Dermatol 1991; 16(6):474-7.

[4] Gianotti R, Alessi E. Clear cell hidradenoma associated with the folliculo-sebaceous-apocrine unit. Histologic study of five cases. Am J Dermatopathol 1997; 19(4):3517.

[5] Dumont K. Humphrays T, Malhotra R. Stump the experts. J Dermatol Rev 1996; 22:998-9.

[6] Cooper PH. Carcinomas of sweat glands. Pathol Annu 1987; 22(Pt 1):83-124.

[7] Elder DE, Murphy GF. Atlas of Tumor Pathology: melanocytic tumors of the skin. 3rd series, fascicle 1. Washington, DC: Armed Forces Institute of Pathology 1991: p. 61-153.

[8] Wick MR, Goellner JR, Wolfe JT, et al. Adnexal carcinomas of the skin II. Extraocular sebaceous carcinomas. Cancer 1985; 56(5):1163-72.

[9] Mehregan AH, Hashimoto K, Rahbari H. Eccrine adenocarcinoma. A clinicopathologic study of 35 cases. Arch Dermatol 1983; 119(2):104-14.

[10] Ohi Y, Umekita Y, Rai Y, et al. Clear cell hidradenoma of the breast: a case report with review of the literature. Breast Cancer 2007; 14(3):307-11.

[11] Volmar KE, Cummings TJ, Wang WH, et al. Clear cell hidradenoma: a mimic of metastatic clear cell tumors. Arch Pathol Lab Med 2005; 129(5):e113-6. 